$$
\begin{gathered}
\text { Uluslararası Sosyal ve Eğitim Bilimleri Dergisi } \\
\text { International Journal of Social and Educational Sciences } \\
\text { Cilt 7, Sayı 14, Aralık } 2020 \text { \& Vol 7, No 14, December } 2020 \\
\text { e-ISSN 2148-8673 } 2020 \text { Telif Hakkı IJOSES'e aittir }
\end{gathered}
$$

DOI: $10.20860 /$ ijoses.835074

http://dergipark.gov.tr/ijoses

http://www.ijoses.com

Geliş Tarihi \& Received: 02.12.2020

Kabul Tarihi \& Accepted: 14.12.2020

IJOSES, 2020, 7(14): 219-232

\title{
İşbirlikli Öğrenme Modelinin Uzaktan Eğitim Ortamlarında Uygulanmasına Yönelik Fen Bilgisi Öğretmen Adaylarının Görüş ve Önerilerinin İncelenmesi
}

Investigation of the Preservice Science Teachers' Views and Suggestions on the Application of the Cooperative Learning Model in Distance Education Environments

\section{Fulya Zorlu*}

$\ddot{O} \mathbf{z}$

$\mathrm{Bu}$ araştırmanın amacı; işbirlikli öğrenme modelinin uzaktan eğitim ortamlarında uygulanmasına yönelik fen bilgisi öğretmen adaylarının görüş ve önerilerinin incelenmesidir. Bu amaç doğrultusunda nitel araştırma yaklaşımlarından durum araştırması yöntemi kullanılmıştır. Araştırmaya bir devlet üniversitesinin fen bilgisi öğretmenliği bölümünün dördüncü sınıfinda öğrenim gören 8 fen bilgisi öğretmen adayı katılmıştır. Araştırmada veri toplama yöntemleri olarak odak grup görüşmesi ve doküman inceleme yöntemleri kullanılmıştır. Araştırmadan elde edilen veriler içerik analizi yöntemiyle analiz edilmiştir. Araştırmadan elde edilen bulgulara göre fen bilgisi öğretmen adaylarının çoğu işbirlikli öğrenme modelinin uzaktan eğitim ortamlarında uygulanmasının faydalı olacağını ifade etmişlerdir. Ayrıca fen bilgisi öğretmen adayları işbirlikli öğrenme modeline ait özelliklerin çoğuna önerilerinde yer vermişlerdir. Fen bilgisi öğretmen adaylarının uzaktan eğitim ortamında işbirlikli öğrenme modelinin uygulanmasına yönelik görüş ve önerileri doğrultusunda Jigsaw öğrenme yöntemine ait uygulama önerisi verilmiştir.

Anahtar Kelimeler: Fen Eğitimi, İşbirlikli Öğrenme Modeli, Pandemi, Uzaktan Eğitim.

\begin{abstract}
The aim of this research was to investigate the preservice science teachers' views and suggestions on the application of the cooperative learning model in distance education environments. The case study method, one of the qualitative research approaches, was used in the research. The eight preservice science teachers who studied in the fourth grade of the science teaching department of a public university participated in the study. The focus group interview and the document review methods were used as data collection methods in the research. The data obtained from the research were analyzed by content analysis method. According to the findings obtained from the research, most of the preservice science teachers stated that it would be beneficial to apply the cooperative learning model in distance education environments. Within the scope of the research, it is seen that the preservice science teachers take part in many of the characteristics of the cooperative learning model in their suggestions. At the end of this research, an application proposal of jigsaw learning method was given in line with the views and suggestions of the preservice science teachers for the application of the cooperation learning model in the distance education environment.
\end{abstract}

Keywords: Cooperative Learning Model, Distance Education, Pandemic, Science Education.

*(Dr. Öğr. Üyesi); Zongulak Bülent Ecevit Üniversitesi, fulya.zorlu @ beun.edu.tr, ORCID: 0000-0001-8167-0839

Kaynak Gösterme: Zorlu, F. "İşbirlikli Öğrenme Modelinin Uzaktan Eğitim Ortamlarında Uygulanmasına Yönelik Fen Bilgisi Öğretmen Adaylarının Görüş ve Önerilerinin İncelenmesi". Uluslararası Sosyal ve Eğitim Bilimleri Dergisi 7 (2020 ): 219-232. 


\section{Extended Summary}

\section{Purpose and Significance:}

The people need to come together to cooperate for reasons such as meeting their needs, solving their problems and putting forward new things. So they can reach their goals more easily and live a better life. Similarly, it is of great importance to cooperate to achieve the goals set in the field of education and to provide better learning. Based on this understanding, the cooperative learning model was put forward and became a popular learning model in line with the advantages it provides today. When studies based on the cooperative learning model are examined, it is seen that all times of these studies and the methods of cooperative learning model used are different, but almost all of them are practices carried out in classroom environments where face-to-face interaction is performed. However, today, as a result of the transformation of coronavirus (COVID-19) into a pandemic in the world, changing conditions do not allow face-to-face education. Within the scope of the measures taken in our country, education-teaching activities continue through distance education and online platforms, television and other media channels connected to the internet are used to ensure the continuation of education. These changes require considering the distance education process during the pandemic and addressing the cooperative learning model. The aim of this research carried out in this context was to investigate the preservice science teachers' views and suggestions on the application of the cooperative learning model in distance education environments.

\section{Methodology:}

The case study method, one of the qualitative research approaches, was used in the research. The eight preservice science teachers who studied in the fourth grade of the science teaching department of a public university participated in the study. The focus group interview and the document review methods were used as data collection methods in the research. The preservice science teachers who participated in the research were asked to prepare proposals for the application of the cooperative learning model in distance education environments in the "Pure Substances and Mixtures" unit. After the suggestions were prepared, a 52-minute focus group interview was formed with the preservice science teachers. The application suggestions prepared by the preservice science teachers were used as a data collection tool. The data obtained from the research were analyzed by content analysis method.

\section{Results, discussion and conclusion:}

According to the findings obtained from the research, most of the preservice science teachers who participated in the research stated that it would be beneficial to apply the cooperative learning model in distance education environments. Within the scope of the research, it is seen that the preservice science teachers take part in many of the characteristics of the cooperative learning model in their suggestions and try to ensure positive commitment through tasks. In addition, it is seen that while of the preservice science teachers is applied of the cooperative learning model in distance education environments, heterogeneous groups will have difficulties in creating a working environment together, duration, teacher's interest in groups and group work process outside the course. At the end of this research, an application proposal of jigsaw learning method was given in line with the views and suggestions of the preservice science teachers who participated in the research for the application of the cooperation learning model in the distance education environment. The jigsaw learning method will be applied in this application. Students will first be tested for information and heterogeneous groups will be formed. Students will prepare and attend classes through the Zoom program. Before starting the lesson, the teacher will open as many rooms as the Zoom program as the number of groups and check that the group members enter their rooms. When heterogeneous groups move to the rooms, they will create their plans and determine their experts in the sub-subjects of the unit according to their knowledge and interests. Then the teacher will take the expert groups to their rooms and check the work of the groups in the time given in the relevant sub-subjects. When experts return to their original groups, group work will be carried out by teaching other group members the sub-subjects they are experts in. During 
the group work, the teacher will go to all groups at certain time intervals and check the studies. The questions asked during the check will also be written in the chat section of the program and will be seen by all students. After the group work is finished, the whole class will come together and the presentation group and question group will be determined by the lottery. While presenting the presentation group, other students will write the questions in the chat section. The question group will ask the questions within the framework of the integrity of the subject. Outside of the lesson, groups will create a working environment by establishing different groups through zoom program, social media applications and WhatsApp. Group work will be tried to be provided outside the lesson. The evaluation phase will be done individually and as a group. The purpose of creating group points is to understand the importance of the group and to ensure that it is connected to each other. After the evaluations, the application will be terminated.

\section{Giriş}

İnsanlar ihtiyaçlarını gidermek, sorunlarını çözmek ve yeni şeyler ortaya koymak gibi sebeplerle bir araya gelerek iş birliği yapma gereksinimi duyarlar. Böylece hedeflerine daha kolay ulaşabilir ve daha iyi bir yaşam sürebilirler. Benzer şekilde, eğitim alanında belirlenen hedeflere ulaşabilmek ve daha iyi bir öğrenme sağlamak için iş birliği yapmak büyük önem taşımaktadır. Bu anlayıştan yola çıkılarak işbirlikli öğrenme modeli ortaya atılmış ve günümüzde sağladığı avantajlar doğrultusunda popüler bir öğrenme modeli olmuştur.

İşbirlikli öğrenme modeli; öğrencilerin ortak bir amaç doğrultusunda heterojen gruplar halinde iş birliği içinde çalışmalarını ve böylece sorumluluk alarak hem kendi hem de diğer öğrencilerin kapasitelerini artırmalarını sağlayan süreç odaklı bir öğrenme modelidir (Açıkgöz, 1992; Barkley, Cross \& Major, 2005; Johnson \& Johnson, 2014; Sharan, 2015; Siegel, 2005). İşbirlikli öğrenme modelini uygulamak için olumlu karşılıklı bağlılık, yüz yüze etkileşim, kişilerarası ve küçük grup becerileri, bireysel ve grup hesap verebilirliği ve grup işleme unsurlarının dikkate alınması gereklidir (Johnson, Johnson \& Holubec, 2013). $\mathrm{Bu}$ ilkelere uygun olarak düzenlenen işbirlikli öğrenme ortamlarında modele ait birçok yöntem kullanılmaktadır. Bunlar arasında "Birlikte Öğrenme", "Takım-Oyun-Turnuva", "Birleştirilmiş İş̧birlikli Okuma ve Kompozisyon (Yazma)", "Jigsaw", "Grup Araştırması", "Takım Destekli Bireyselleştirme", "Işbirliği-İş̧birliği”, "Öğrenci Takımları Başarı Bölümleri” ve "Akademik Çelişki” yöntemleri yaygın olarak kullanılanlardır (Colosi \& Zales, 1998; Hines, 2008; Johnson, Johnson \& Holubec, 2013; Johnson, Johnson \& Stanne, 2000).

İşbirlikli öğrenme modeli tüm öğrencilerin sahip oldukları potansiyellerini kullanmalarını, birbirleriyle olumlu bağlar oluşturmalarını, eleştirel düşünme, bilgi üretebilme, sorun çözebilme gibi özellikler kazanarak topluma yararlı bireyler yetiştirilmesini sağlayarak kişisel, grupsal ve toplumsal yararlar sağlar (Bayrakçeken, Doymuş \& Doğan, 2013; Lara \& Reparaz, 2009; Patesan, Balagiu \& Zechia, 2016; Şimşek, 2007; Zorlu, 2016). İşbirlikli öğrenme ortamlarında istenen yararları sağlayabilmede öğretmenlerin önemli rol ve sorumlulukları vardır (Gillies \& Boyle, 2010; Loh \& Ang, 2020). Bu süreçte öğretmenler hedefler belirleyerek, görevleri planlayarak, öğrencileri gruplara atayarak öğrencilerin etkileşimlerini düzenler ve desteklerler. (Abramczyk \& Jurkowski, 2020, Johnson, Johnson \& Holubec, 1994; Slavin, 2012). Böylece her bir öğrencinin sürece aktif katılımını sağlayarak gelişimleri için uygun öğrenme ortamları oluştururlar.

Son yıllarda özellikle fen eğitiminde işbirlikli öğrenme çalışmalarının arttığı görülmektedir (Khalil \& Aldridge, 2019; Kim, 2018; Nadrah, Ismail \& Muhammad Sidin, 2017; Okumuş, 2020; Okumuş \& Doymuş, 2018; Rosiani, Parmin \& Taufiq, 2020; Yılayaz \& Barata-Aksoy, 2020; Yıldız, Çalıklar \& Şimşek, 2020; Zorlu \& Sezek, 2019a; Zorlu \& Sezek, 2020). Söz konusu bu çalışmaların gerçekleştirilme süreleri ve kullanılan işbirlikli öğrenme yöntemleri farklı olmakla birlikte, hemen hepsinin yüz yüze etkileşim kurulan sınıf ortamlarında gerçekleştirilen uygulamalar olduğu görülmektedir. Ancak günümüzde koronavirüsün (COVID-19) dünyada bir pandemiye dönüşmesi neticesinde değişen şartlar yüz yüze eğitime imkan vermemektedir. Bu süreçte ülkemizde alınan tedbirler kapsamında eğitim-öğretim faaliyetleri uzaktan eğitim yoluyla devam etmekte ve eğitimin devamını sağlamak için internete bağl çevrim içi platformlar, televizyon 
ve diğer medya kanalları kullanılmaktadır (Can, 2020). Bu durum öğretmen ve öğrencilerin aynı yerlerde olmadığı sanal eğitim ortamlarını ifade etmektedir. Eğitimin sanal ortamlarda gerçekleştirilmesi ise birçok zorluk ve kısıtlamaları barındırabilmektedir (Bakioğlu \& Çevik, 2020). Her şeyden önce bu ortamlarda belirlenen hedeflere ulaşmak için öğretmenlerin bilgi ve deneyimlerini kullanarak öğrenme sürecini yeni eğitim ortamlarına adapte etmesi gerekmektedir (Gómez, 2020). Dolayısıyla bu ortamlar birçok teknolojik donanımı ve yazılımı kullanmayı gerektirmektedir (Mulenga \& Marbán, 2020). Ayrıca eğitimin sanal ortamlarda gerçekleştirilmesi sosyal tutumları da önemli ölçüde etkilemektedir (Lee, 2020). Yaşanan bu değişimler pandemi sırasında uzaktan eğitim sürecini göz önünde bulundurarak işbirlikli öğrenme modelini ele almayı gerektirmektedir. Uzaktan eğitim ortamlarında işbirlikli öğrenme modelinin uygulanmasına yönelik öneriler ileride yapılacak çalışmalara rehber olacaktır. Bu bağlamda gerçekleştirilen bu araştırmanın amacı; işbirlikli öğrenme modelinin uzaktan eğitim ortamlarında uygulanmasına yönelik fen bilgisi ögretmen adaylarının görüş ve önerilerinin incelenmesidir.

\section{Yöntem}

$\mathrm{Bu}$ araştırmada nitel araştırma yaklaşımlarından durum araştırması yöntemi kullanılmıştır. Durum araştırması yöntemi, bir olgunun ya da olayın araştırmacı tarafindan müdahale olmadan gerçek ortamında araștırılmasıdır (Creswell, 2007; Yıldırım \& Șimșek, 2011). Bu doğrultuda araştırmada fen bilgisi öğretmen adaylarının uzaktan eğitim ortamlarında işbirlikli öğrenme modelinin uygulanması durumuna yönelik görüşleri ve önerileri incelenmiştir. Araştırmanın gerekli etik kurul onayı alınmıştır.

\section{Örneklem}

Araştırmada amaçlı örnekleme yöntemlerinden uygun örnekleme yöntemi ile örneklem belirlenmiştir. Fen bilgisi öğretmenliği bölümünün dördüncü sınıfında öğrenim gören ve Okul Deneyimi dersi alan fen bilgisi öğretmen adaylarının işbirlikli öğrenme modeli konusunda bilgileri vardır ve üniversite eğitimleri ile Okul Deneyimi dersi kapsamında ortaokullarda uzaktan eğitim ortamlarının uygulanmasını görmektedir. Uzaktan eğitim ortamlarında bulunma ve işbirlikli öğrenme modeli konusunda bilgi sahibi olma durumları göz önüne alınarak araştırmada uygun örneklem seçilmiştir. Bu doğrultuda bir devlet üniversitesinin fen bilgisi öğretmenliği bölümünün dördüncü sınıfında öğrenim gören 8 fen bilgisi öğretmen adayı (5 kadın ve 3 erkek) araştırmaya katılmıştır. Araştırmaya katılan fen bilgisi öğretmen adaylarının isimleri yerine odak grup görüşmesinde takma isimler kullanılmıştır.

\section{Veri toplama yöntemleri ve araçları}

Araştırmada veri toplama yöntemleri olarak odak grup görüşmesi ve doküman inceleme yöntemleri kullanılmıştır. Araştırmaya katılan fen bilgisi öğretmen adaylarından "Saf Maddeler ve Karışımlar" ünitesinde işbirlikli öğrenme modelinin uzaktan eğitim ortamlarında uygulanmasına yönelik öneriler hazırlamaları istenmiş ve süre olarak bir hafta verilmiştir. Öneriler hazırlandıktan sonra fen bilgisi öğretmen adayları ile 52 dakika süren odak grup görüşmesi gerçekleştirilmiştir. Odak grup görüşmesinde durum olarak işbirlikli öğrenme modelinin uzaktan eğitim ortamlarında uygulanması verilmiştir. Öğretmen adaylarının hazırlamış oldukları uygulama önerileri veri toplama aracı olarak kullanılmıştır.

\section{Verilerin analizi}

Odak grup görüşmesindeki fen bilgisi öğretmen adaylarının isimleri yerine takma isimler kullanılarak diyalog oluşturulmuştur. Odak grup görüşmeleri ve uygulama örneklerinden elde edilen veriler içerik analiz yöntemi ile analiz edilmiştir. Araştırmadan elde edilen veriler iki araştırmacı (fen eğitimi alanında öğretim üyesi) tarafından bağımsız ve tarafsız bir biçimde analiz edilmiştir. Sonuçlar bir araya getirilerek uyum indeksine bakılmış ve uyum indeksi \%89 olarak belirlenmiştir. Daha sonra iki araştırmacının analizlerindeki farklı noktalar için ortak karar alınmış ve analize son hali verilmiştir. 


\section{Bulgular}

İşbirlikli öğrenme modelinin uzaktan eğitim ortamlarında uygulanmasına yönelik olarak araştırmaya katılan fen bilgisi öğretmen adayları ile gerçekleştirilen odak grup görüşmesine ait diyalog aşağıda verilmiştir.

Moderatör: "İşbirlikli öğrenme modelinin uzaktan eğitim ortamlarında uygulanmasına yönelik görüşleriniz nelerdir?"

Sema: "Derslerin kalıcı olacağını düşünüyorum. Sosyal açıdan iyi olacağını düşünüyorum. İşbirlikli öğrenme modelinin uygulanması için Zoom programı üzerinden giriş yapılıp, dört kişilik gruplar oluşturulacak. Gruplar sisteme ayrı ayrı girecekler. Deney ve etkinlikleri gruptaki herkes sırasıyla yapacak. Sonra ortak bir canlı yayın yapılarak turnuva yapılacak. Ama bu durum süre konusunda olumsuz olabilir."

Çiçek: "Uygulamanın zor olacağını düşünüyorum; fakat öğrencilerin konularda ne öğrendiklerini fark etmelerini sağlayabilir. Birbiriyle iletişim kurmalarını sağlayabilir. Sosyalleşmeyi ve konuyu daha iyi anlamalarını sağlayabilir."

İlhan: "Bireysel olarak öğrenen öğrenciler başarılı olmayabilir. Grupça iyi öğrenen öğrenciler için daha iyi olabilir. Öğrencilerin birlikte çalışmaları sağlanırsa iletişimleri gelişebilir. Bu modelin uzaktan eğitim ortamlarında uygulaması bireysel öğrenen öğrenciler için çok fazla eğitici ve öğretici olmayabilir."

Ali: "Yüz yüze eğitimde faydalı bir öğrenme modelidir; fakat uzaktan eğitim ortamında uygulaması etkili olamayabilir. Grup çalışması yapmakta zorlandığımız için."

Ela: "Uzaktan eğitim ortamında eğer uygulanabilirse çok fazla etkili olacaktır."

Yağmur: "Grup çalışması yapıldığı ve yapılandırmacı anlayışa dayalı bir öğrenme modeli olduğu için en pasif öğrencinin bile süreçte aktif olmasını sağlayacağını düşünüyorum. Uzaktan eğitim ortamında uygulayıp sonuçlarına bakarak ne kadar etkili olduğuna karar verilebilir. Bu açıdan uzaktan eğitim ortamında uygulanması gereklidir."

Fulya: "Uzaktan eğitim ortamlarında işbirlikli öğrenme modeli kullanılabilir. Öğrencilerin farklı kişisel özelliklere sahip olması akranlarıyla arasında olumlu bağlılık yaratacağından dolayı işbirlikli öğrenme modelinin uygulanması etkili olacaktır."

Ayşe: "Uygulanması biraz zor. Fakat uzaktan eğitim ortamlarında işbirlikli öğrenme modeli gibi farklı öğrenme modellerinin uygulanması öğrencilerin kendilerini okulda gibi hissetmelerini sağlayacak ve ders çalışmaya teşvik edecektir. Ders esnasında ve ders dışında grup çalışmaları yaparak iletişim içinde olabilir."

Veli: "Uzaktan eğitim ortamında doğru bir uygulama yapılması faydalı olur. Gayet zevkli bir öğrenme ortamı sağlayacaktır. Keşke yüz yüze eğitimde, geçmişte, bize de uygulasalardı. Özellikle öğrenilmesi zor olan konularda uygulanması daha iyi olacaktır."

Fatma: "İşbirlikli öğrenme modelinin uzaktan eğitim ortamlarında uygulanması öğrencilerin sosyal gelişimine katkılar sağlayacağı için iyi olur. Başarı seviyesini artıracağını düşünüyorum. Uzaktan eğitimde grup çalışması aşamalarının uygulanmasında yaşanan güçlüklerden dolayı zorlayıcı olacağını düşünüyorum."

Yağmur: "Uzaktan eğitim Zoom ve EBA gibi programlarla yapıldığı için öncelikle öğrencilerin bu programları çok iyi öğrenmesini sağlamalıyız ve sürece adapte olmalarına dikkat etmeliyiz. Öğrenciler sosyal medya ve WhatsApp uygulamalarını çok iyi kullanıyorlarsa sürece dahil edilebilir. Ayrılıp-birleştirme yönteminde sosyal medya ve WhatsApp kullanılabilir."

Sema: "5. sınıfa giden yeğenim uzaktan eğitim dersleri için bilgisayarın başına oturmak istemiyor. Başkalarının da bunu yaptığına inanmayıp sadece kendisinin yaptığına inanıyor. 
Derslere öğrencilerin ilgilerini çekmek gerekiyor. Bu durumu düşünerek 5. sınıf öğrencilerine değil de daha çok 7. ve 8.sınıf öğrencilerine uygulanmasını öneririm."

Yağmur: "Sema'nın dediği ilgi çekici olma konusunda işbirlikli öğrenme modeli uygulanabilir ve grup çalışması ders dışında sağlanırsa okul ortamına daha yakın bir ortam oluşturulabilir. Bence çocukların anlamakta sıkıntı yaşadığı konularda işbirlikli öğrenme modeli uzaktan eğitim ortaminda uygulanabilir."

Çiçek: "Grup çalışması yapılmasının zor bir süreç olacağını düşünüyorum. Uzaktan eğitim programları ile sosyal medya uygulamalarını kullanarak işbirlikli öğrenme modeli uygulayabiliriz."

Fatma: "Uzaktan eğitim ortamlarına sınıftaki bütün öğrencilerin katılımı sağlanırsa ve şartlar elverişli olursa (internet kopmaması gibi) ancak bu modeli uygulayabiliriz."

Fulya: "Uzaktan eğitim ortamlarında işbirlikli öğrenme modelinin uygulanması gerektiğini düşünüyorum. Dikkat çekebilir, güdüleme yapar. Uzaktan eğitim ortamlarında işbirlikli öğrenme modeli uygulanırken olumlu bağlılığı sağlamak için görev paylaşımı yapılabilir. Öğrenciler birbirleriyle iş birliği yapmak durumunda olduklarında bağımlı olurlar."

Yağmur: "Jigsaw öğrenme yöntemini uzaktan eğitim ortamında uygularsak, öğrenciler en az bir konuda uzman olacaklarından en pasif öğrenci bile süreçte aktif olacaktır."

İlhan: "Ders dişında grup çalışması olarak etkinlikler hazırlatılarak etkileşimi sağlayabiliriz. Olumlu bağlılı̆̆ bu şekilde sağlayabiliriz."

Yağmur: "Örneğin gruplardaki öğrenciler deneyleri yaparken hatalı olan kısımları diğer öğrencilerin söylemesi ile grup çalışması yapılabilir. Ders dışında Zoom, sosyal medya uygulamaları ve WhatsApp kullanılarak grup çalışması yaptırabilir.”

Fulya: "Zoom uygulamasında öğrencileri heterojen gruplara ayırdıktan sonra, aynı oturumda farklı odalar açılarak grupların kendi aralarında ve diğer gruplardan bağımsız bir şekilde çalışmaları sağlanabilir. Öğretmen grupları ara ara bu özel odalara girerek kontrol edebilir. Bunun için Zoom programının aynı oturumda öğrencileri gruplara ayırma özelliği kullanılabilir. $\mathrm{Bu}$ durumda öğretmen tüm gruplara girebilmektedir. Aynı grupta olanlar birbiriyle etkileşim içinde bulunabilir."

Sema: "Fulya' in söylediği özelliği yeni öğrendim. Bu özellik sayesinde uzaktan eğitim ortamında işbirlikli öğrenme modeli çok rahat bir şekilde uygulanabilir."

Fatma: "Öğrenciler grup çalışması bittiğinde bir araya gelirler. Kura ile iki grup çekilir. Bir grup sunum grubu, diğer grup soru grubu olur. Sunum grubu sunumu yaparken sinıf soruları sohbet kısmına yazabilirler. Soru grubu yazılan bu sorulardan uygun olanları belirleyerek sunum grubuna sorabilir."

Ela: "Ders dışında da saatler belirlenip grupların çalışması sağlanabilir. Öğrencilerin ders dışında araştırma yapmaları ve derse gelmeden önce çalışmalarını grup arkadaşlarıyla iletişime geçerek aralarında konuşmaları gerekmektedir."

Ali: "Gruplar çalışırken WhatsApp grupları da oluşturulabilir ve buradan yazılı doküman paylaşımı yaparak ders dışında da gruplar etkileşimli olabilir."

Odak grup görüşmesinde işbirlikli öğrenme modelinin uzaktan eğitim ortamlarında uygulanmasına yönelik fen bilgisi öğretmen adaylarının görüşleri incelediğinde "Sağlayacağı Yararlar", "Yaşanabilecek Zorluklar" ve "Öneriler" olmak üzere üç tema belirlenmiştir. Sağlayacağı Yararlar temasında fen bilgisi öğretmen adaylarının görüşlerinde sosyalleşme, etkileşim sağlama, aktif olma, başarıyı artırma, kalıcı öğrenmeyi sağlama, öğrendiklerinin farkında olma, aktif öğrenmeyi sağlama, okul ortamı sağlama, ders çalışmaya teşvik etme, ilgi çekme ve öğrenmeyi güdüleme olarak ifade ettikleri görülmektedir. En çok sağladığı yarar olarak sosyalleşme, etkileşim, aktif öğrenme ve okul ortamı oluşturması olarak 
vurgulanmıştır. "Yaşanabilecek Zorluklar" temasında fen bilgisi öğretmen adaylarının görüşlerinde heterojen grupların birlikte çalışma ortamının oluşturulması, süre, öğretmenin gruplarla ilgilenmesi ve ders dışında grup çalışması süreci konularındaki zorlukları ifade ettikleri görülmektedir. Ayrıca fen bilgisi öğretmen adayları odak grup görüşmesinde, yaşanabilecek zorluklara önerilerde bulunarak işbirlikli öğrenme modelinin uzaktan eğitim ortamlarında uygulanmasını ifade ettikleri görülmektedir. "Öneriler" temasında fen bilgisi öğretmen adaylarının görüşleri incelediğinde Zoom programı ile sınıfın farklı gruplara ayrılması ve grupların sadece kendi içinde etkileşimde olması, öğretmenlerin grupları kontrol ederek rehberlik etmesi, sürecin sonunda bütün sınıfın bir araya gelerek kura ile grupların seçilip sunumların yapılması ve sunum yapan gruba sorular sorulması üzerinde en çok durdukları belirlenmiştir. Ayrıca fen bilgisi öğretmen adaylarının uygulamaya geçmeden önce, öğrencilerin uzaktan eğitim programlarını ve sosyal medya uygulamalarını iyi öğrenip bu uygulamaların kullanılmasına adapte olmasını, işbirlikli öğrenme modelinin özellikle zor konularda uygulanmasını, sınıf seviyelerinde dikkat çekme sürecininin etkili kullanılmasını, olumlu bağlılık için görev paylaşımı yapılmasını, sınıf dışında grupların araştırma ve çalışma yapmaları için uzaktan eğitim programlarının ve sosyal medya kanallarının kullanılmasını ve heterojen grupların kendilerine WhatsApp grubu kurup yazılı doküman paylaşımı yapılmasını önerdikleri görülmektedir. Genel olarak değerlendirildiğinde; işbirlikli öğrenme modelinin uzaktan eğitim ortamlarında uygulanmasının fen bilgisi öğretmen adaylarının çoğunun etkili olacağını, sadece bir öğretmen adayının etkili olmayacağını ifade ettiğ görülmektedir.

Araştırmaya katılan fen bilgisi öğretmen adaylarının uzaktan eğitim ortamlarında işbirlikli öğrenme modelinin uygulanmasına yönelik olarak verdikleri önerilerinden elde edilen verilerin içerik analizi Tablo 1 'de verilmiştir.

Tablo 1. İşbirlikli Öğrenme Modeline Ait Önerilerin İncelenmesi

\begin{tabular}{|c|c|c|}
\hline Temalar & Kodlar & Frekans \\
\hline \multirow{3}{*}{ Tercih Edilen Öğrenme Yöntemi } & Jigsaw (Ayrılıp Birleşme) & 5 \\
\hline & Öğrenci Takımları Başarı Bölümleri & 2 \\
\hline & Grup Araştırması & 1 \\
\hline \multirow{3}{*}{ Heterojen Gruplardaki Öğrenci Sayısı } & Üç Öğrenci & 4 \\
\hline & Dört Öğrenci & 3 \\
\hline & İki Öğrenci & 1 \\
\hline \multirow{2}{*}{ Farklı Öğrenme Teknikleri } & Soru -Cevap & 4 \\
\hline & Beyin Firtınası & 1 \\
\hline \multirow{2}{*}{ Grup İçinde Görev Paylaşımı } & Var & 7 \\
\hline & Yok & 1 \\
\hline \multirow{7}{*}{ Programlar ve Uygulamalar } & Zoom & 8 \\
\hline & WhatsApp & 4 \\
\hline & EBA & 4 \\
\hline & Yotube & 4 \\
\hline & Sosyal Medya Uygulamaları & 2 \\
\hline & Google Drive & 2 \\
\hline & Google Meet & 1 \\
\hline \multirow{3}{*}{ Ders Dışında Çalışma Süreci ve Özelliği } & Derse Ön Hazırlık & 8 \\
\hline & $\begin{array}{l}\text { Ders Dışında Grupların Uzaktan Eğitim Ortamında } \\
\text { Çalışmaları }\end{array}$ & 5 \\
\hline & Ders Dışında Bireysel Çalışma & 3 \\
\hline \multirow{3}{*}{ Değerlendirme } & Bireysel ve Grup & 6 \\
\hline & Bireysel & 1 \\
\hline & Grup & 1 \\
\hline \multirow{2}{*}{ Grup Lideri } & Yok & 6 \\
\hline & Var & 2 \\
\hline
\end{tabular}


Tablo 1'de fen bilgisi öğretmen adaylarının uzaktan eğitim ortamlarında işbirlikli öğrenme modelinin uygulanmasına yönelik önerileri incelenerek "Tercih Edilen Öğrenme Yöntemi”, "Heterojen Gruplardaki Öğrenci Sayısı", "Farklı Öğrenme Teknikleri”, "Grup İçinde Görev Paylaşımı", "Programlar ve Uygulamalar", "Ders Dışında Çalışma Süreci ve Özelliği”, "Değerlendirme" ve "Grup Lideri" olmak üzere 8 tema belirlenmiştir. Tercih Edilen Öğrenme Yöntemi temasında fen bilgisi öğretmen adaylarının önerileri incelediğinde jigsaw, ögrenci takımları başarı bölümleri ve grup araştırması yöntemlerinin yer aldığı; en çok jigsaw öğrenme yönteminin uygulamasına yönelik öneriler olduğu görülmektedir. Heterojen Gruplardaki Öğrenci Sayısı temasında araştırmaya katılan fen bilgisi öğretmen adaylarının önerileri incelediğinde öğrenci sayısının iki, üç ve dört öğrenci olarak tercih edildiği; en çok üç ögrenci tercih edildiği, en az ise iki öğrenci tercih edildiği görülmektedir. Farklı Öğrenme Teknikleri temasında fen bilgisi öğretmen adaylarının önerileri incelediğinde farklı öğrenme teknikleri olarak soru-cevap ve beyin firtınası tekniklerine yer veren önerilerde bulundukları görülmektedir. Grup İçinde Görev Paylaşımı temasında fen bilgisi öğretmen adaylarının önerileri incelediğinde yedi öneride görev paylaşımı yapılırken bir öneride yapılmamıştır. Programlar ve Uygulamalar temasında fen bilgisi ögretmen adaylarının önerileri incelediğinde Zoom, WhatsApp, EBA, Youtube, sosyal medya uygulamaları, Google Drive ve Google Meet program ve uygulamalarına yer verildiği görülmektedir. Zoom programı bütün önerilerde kullanılmıştır. Ders Dışında Çalışma Süreci ve Özelliği temasında fen bilgisi öğretmen adaylarının önerileri incelediğinde derse gelmeden önce konuya yönelik ön hazırlık, ders dışında grup çalışması ve ders dışında bireysel çalışma yapılması yer almaktadır. Önerilerin tamamında derse gelmeden önce konuya yönelik ön hazırlık yapılmasının yer aldığı görülmektedir. Değerlendirme temasında fen bilgisi öğretmen adaylarının önerileri incelediğinde bireysel ve grup, sadece bireysel ve sadece grup olarak değerlendirmelere yer verildiği görülmektedir. Önerilerde etkileşim ve bağlılık olması açısından grup değerlendirilmesine yer verilmiştir. Grup Lideri temasında fen bilgisi öğretmen adaylarının önerileri incelediğinde önerilerin çoğunda grup lideri seçilememiştir. Hazırlanan sadece iki öneride grup lideri belirlenmiştir.

\section{Sonuç, Tartışma ve Öneriler}

$\mathrm{Bu}$ araştırmada işbirlikli öğrenme modelinin uzaktan eğitim ortamlarında uygulanmasına yönelik fen bilgisi öğretmen adaylarının görüş ve önerileri incelenmiştir. Araştırmada gerçekleştirilen odak grup görüşmesinden ve fen bilgisi öğretmen adaylarının uygulama önerilerinden elde edilen bulgulara ait sonuçlar, tartışmalar ve öneriler bu bölümde ilgili alanyazın ile desteklenerek verilmiştir.

Araştırmada odak grup görüşmesinden ve uzaktan eğitim ortamlarında işbirlikli öğrenme modelinin uygulanmasına yönelik önerilerden elde edilen bulgulara göre fen bilgisi öğretmen adaylarının çoğu işbirlikli öğrenme modelinin uzaktan eğitim ortamlarında uygulanmasının faydalı olacağını ifade etmişlerdir. İlgili alanyazında işbirlikli öğrenme modelinin yüz yüze uygulanmasının öğrencileri birçok alanda geliştirdiği sonucuna ulaşılan çok fazla çalışmanın olduğu görülmektedir (Aksoy, 2011; Arreguin-Anderson \& Esquierdo, 2011; Gambari, Yusuf \& Thomas, 2015; Orprayoon, 2014; Şimşek, Doymuş \& Karaçöp, 2008; Zorlu \& Sezek, 2016; Zorlu \& Sezek, 2019a, 2019b; Zorlu \& Sezek, 2020). Bundan dolayı işbirlikli öğrenme modelinin uzaktan eğitim ortamında uygulanmasının da çok faydalı olacağı düşünülmektedir.

Odak grup görüşmesinden elde edilen bulgularda fen bilgisi öğretmen adayları işbirlikli öğrenme modelinin uzaktan eğitim ortamlarında uygulanmasının sosyalleşme, iletişim, etkileşim, aktif öğrenme ve okul ortamına benzer bir ortam sağlayacağını belirttikleri; bunlara ilave olarak başarıyı artırma, kalıcı öğrenmeyi sağlama, öğrendiklerinin farkında olma, ders çalışmaya teşvik etme, ilgi çekme ve öğrenmeyi güdüleme gibi yararlar sağlayacağını ifade ettikleri görülmektedir. Elde edilen bulgulara göre işbirlikli öğrenme modelinin uzaktan eğitim ortamlarında uygulanmasının çok faydalı olacağı söylenebilir. İlgili alanyazında uzaktan eğitim ortamlarında iletişıim ve sosyalleşmenin önemli olduğunu ve bunun sağlanması gerektiği üzerinde durulmuştur (Bakioğlu \& Çevik, 2020; Baytiyeh, 2019; Cheng \& Chau, 2016; Lee, 2020). Uzaktan eğitim sosyal ilişkilerin kurulması ve sürdürülmesi için karmaşık bir süreci içermektedir (Panigrahi, Srivastava \& Sharma, 2018). Lee (2020) çalışmasında COVID-19 kaygısının sosyal tutumları önemli ölçüde etkilediğini bulunmuştur. Baytiyeh (2019), okulun kapatılması sırasında iletişimin sağlanması ve 
sürdürülmesi gerektiğini vurgulanmıştır. Yaşanan pandemi sürecinde alınan tedbirler kapsamında eğitimöğretim faaliyetleri uzaktan eğitimle gerçekleştirildiği için öğretmen, öğrenci ve velilerin iletişim içinde olması üzerinde durulması gereken önemli durumlar arasındadır (Burke, 2020). Uzaktan eğitimde öğrencilerin iletişim becerilerinin oldukça düşük olduğu sonucundan dolayı bu süreçte sosyal ilişkilerin dijital olarak da devam ettirilmesi oldukça önemlidir (Bakioğlu \& Çevik, 2020). İşbirlikli öğrenme modelinin en önemli özelliklerinden biri de sosyalleşme ve iletişim sağlamasıdır (Bayrakçeken, Doymuş \& Doğan, 2013). İşbirlikli öğrenme modelinin uzaktan eğitim ortamlarında uygulanmasının iletişim ve sosyalleşme açısından yararları olacaktır. Fen bilgisi öğretmen adayları uzaktan eğitim derslerinde işbirlikli öğrenme modelinin uygulanmasının okul ortamına benzer bir ortamın oluşturulması ile derslerin daha zevkli olmasını, iletişim ve etkileşimli aktif öğrenme ile öğrenilmesini ve öğrencilerden derslerden daha fazla verim almasını sağlayacağını düşünerek yararlı olacağını ifade ettikleri söylenebilir. İlgili alanyazında yapılan çalışmalarda öğrencilerin uzaktan eğitimde bir okul ortamı oluşmadığından derslerden verim alamadıklarını, derslerin zevkli geçmediğini ve ev ortamında derslere motive olamadıklarını ifade ettikleri sonuçlarına ulaşıldığ 1 görülmektedir (İbicioğlu \& Anatalyalı, 2005; Paydar \& Doğan, 2019; Pınar \& Dönel-Akgün, 2020a, 2020b). Benzer şekilde, uzaktan eğitimde fen bilimleri öğretmenleriyle yapılan araştırmalarda öğrencilerin motivasyonlarının düşük olduğu sonucuna ulaşılmıştır (Bakioğlu \& Çevik, 2020; Sintema, 2020). Derse ilgi çekilmesi, derslerin zevk alınacak hale getirilmesi ve konuların daha iyi öğrenilmesi motivasyonu geliştirir (Akbaba, 2006; Yüksel, 2004). İşbirlikli öğrenme modeli farklı yetenek, sosyal beceri, öğrenme stili, ilgi ve ihtiyaçları olan öğrencilerin bir araya gelerek birlikte çalışmasını sağlamasından dolayı öğrenci motivasyonlarını artırmada etkilidir (Christison, 1990; Genç \& Şahin,2015). Bu bağlamda işbirlikli öğrenme modelinin uzaktan eğitimde uygulanması öğrencilerin motivasyon düzeylerini artırabilir.

Odak grup görüşmesinden elde edilen bulgularda fen bilgisi öğretmen adaylarının işbirlikli öğrenme modelinin uzaktan eğitim ortamlarında uygulanırken heterojen grupların birlikte çalışma ortamının oluşturulması, süre, öğretmenin gruplarla ilgilenmesi ve ders dışında grup çalışması süreci konularında zorluklar yaşanacağını ifade ettikleri görülmektedir. İlgili alanyazında uzaktan eğitimle ile ilgili yapılan araştırmalarda öğretmen-öğrenci etkileşiminde zorluklar yaşadığ 1 ve bazı aksaklıklar yaşandığı sonucuna ulaşılmıştır (Pınar \& Dönel-Akgün, 2020a, 2020b). İşbirlikli öğrenme modeli uzaktan eğitim ortamlarında uygulanırken grup çalışmasına ve zamanı iyi kullanmaya önem verilmesi gerektiği söylenebilir.

Odak grup görüşmesinden elde edilen bulgularda fen bilgisi öğretmen adayları işbirlikli öğrenme modelini uzaktan eğitim ortamlarında uygularken Zoom programı kullanılması ile sınıfın farklı gruplara ayrılması, grupların sadece kendi içinde etkileşimde olması, öğretmenlerin grupları kontrol ederek rehberlik etmesi, sürecin sonunda bütün sınıfın bir araya gelerek kura ile grupların seçilip sunumların yapılması ve sunum yapan gruba sorular sorulması uygulama önerisi üzerinde en çok durmuşlardır. Ayrıca işbirlikli öğrenme modelinin özellikle zor konularda uygulanmasını, olumlu bağl11ı için görev paylaşımı yapılmasını, sınıf dışında grupların araştırma ve çalışma yapmaları için uzaktan eğitim programlarının ve sosyal medya kanallarının kullanılmasını önerdikleri görülmektedir. Araştırmaya katılan öğretmen adayları Zoom programının gruplar oluşturma özelliğinden dolayı (URL-1) önerilerinde bu programın kullanımına yer vermiş olabilirler. Fen bilgisi öğretmen adaylarının uzaktan eğitim ortamlarında işbirlikli öğrenme modelinin uygulanmasına yönelik önerilerinde en çok Jigsaw öğrenme yöntemini, heterojen gruplardaki öğrenci sayısının üç veya dört öğrenci olmasını, iletişim için soru-cevap öğrenme tekniğini kullanmayı, grup içi görev paylaşımı olmasını, Zoom programını kullanmayı, derse gelmeden önce öğrencilerin mutlaka ön hazırlık yapmasını, ögrenci değerlendirmelerinin bireysel ve grup olarak yapılmasını, grupların grup lideri olmadan çalışmasını önermişlerdir. Elde edilen bulgulara göre fen bilgisi öğretmen adayları işbirlikli öğrenme modeline ait özelliklerin çoğuna önerilerinde yer verdikleri söylenebilir.

Araştırmaya katılan fen bilgisi öğretmen adaylarının uzaktan eğitim ortamlarında işbirlikli öğrenme modeli uygulanırken en çok jigsaw öğrenme yöntemini tercih ettikleri görülmektedir. Jigsaw yöntemi, yapılandırılmış akran öğretimi ile öğrenci etkileşimini teşvik ederek öğrenci performansında ve ögrenme motivasyonunda kazanımlar sağlamak için tasarlanmıştır (Aronson \& Bridgeman, 1979; Oakes, Hegedus, Ollerenshaw, Drury \& Ritchie, 2018). Bu yöntemde her bir alt konuyu çalışmak üzere oluşturulan uzman 
gruplar ve konunun alt konularını birbirine öğretmek için oluşturulan asıl gruplar vardır (Johnson, Johnson \& Holubec, 2012; Şimşek, 2012). Jigsaw gruplarında öğrenciler işbirliği görevlerini yapabilmek için önceki araştırmalardan yararlanarak çalışırlar ve hem sınıf içi hem de sınıf dışı tartışmalara aktif olarak katılarak bilgilerini artırma imkanı bulurlar (Doymuş, 2008). Bu yönüyle jigsaw yöntemi akademik bir konuyu iletişim becerilerini de geliştirerek öğrenmenin ve uzun vadeli başarılı olmanın en etkili yollarından biri olarak değerlendirilebilir (Halimah \& Sukmayadi, 2019; Van Dat, 2016).

İşbirlikli öğrenme modelinin önemli özellikleri olumlu bağll1ık, ferdi sorumluluk, grupların ve grup ruhunun oluşturulması, ögretmenin rolü, sosyal becerilerin kullanılması, yüz yüze etkileşim ve ödüllerdir (Doymuş, 2012). Olumlu bağlılık materyaller veya görevler ile iki farklı strateji ile geliştirebilir (Akkuş, 2013; Sharan \& Sharan, 1992). Araştırmaya katılan fen bilgisi öğretmen adaylarının olumlu bağlılığg görevler yoluyla sağlamaya çalıştığı görülmektedir. Ferdi sorumluluk için öğrencilerin başarılarının bireysel olanın yanında çoğunlukla grup etkinliklerden oluşan grup başarısı oluşturulur (Bayrakçeken, Doymuş \& Doğan, 2013). Araştırmaya katılan fen bilgisi öğretmen adaylarının öğrencilerin başarı değerlendirmesinde ferdi sorumluluklarını geliştirmek için bireysel ve grup başarısını bir arada bulunduran değerlendirmeler yapmayı önerdikleri söylenebilir. Grupların ve grup ruhunun oluşturulması için öğrencilerden başarı, ilgi, beceri gibi birçok özelliklerine göre heterojen gruplar oluşturulur ve grup içinde öğrenciler kendi öğrenmelerinin yanında birbirlerinin öğrenmelerini de en üst düzeye çıkarmak için grupça hareket edip çalışırlar (Macpherson, 2015). Araştırmaya katılan fen bilgisi öğretmen adaylarının birçok özelliği düşünerek öğrencileri heterojen gruplara ayırdığı ve grup başarısının ön plana çıkarılması ile grup ruhunu kazandırmayı sağlamaya çalıştıkları söylenebilir. İşbirlikli süreçte öğretmen öğrencilerle iyi iletişim kurmalı, sürekli etkileşim içinde ve süreci iyi yönlendiren bir rehber konumunda olmalıdır (Bayrakçeken, Doymuş \& Doğan, 2013; Ekinci, 2011). Araştırmaya katılan fen bilgisi öğretmen adayları Zoom programı ile açılan farklı odalar aracılığıyla heterojen grupların çalışmalarının, öğretmenin etkileşim içinde olmasıyla iletişim kurulmasının ve ders dışında grup çalışmalarını takip etmek amacıyla kurulan WhatsApp gruplarında yer alarak öğrenci çalışmalarından haberdar olmasının sağlanmasına yönelik öneriler verdikleri görülmektedir.

Araştırmaya katılan fen bilgisi öğretmen adaylarının işbirlikli öğrenme modelinin uzaktan eğitim ortamlarında uygulanmasına yönelik odak grup görüşmesi ve önerilerinden elde edilen bulgulardan hareketle bir örnek öneri uygulaması oluşturabilir. Bu uygulamada jigsaw öğrenme yöntemi uygulanacaktır. Öğrencilere öncelikle bilgi testi yapılıp heterojen gruplar oluşturulacaktır. Öğrenciler ön hazırlık yapacak ve Zoom programı aracılığıyla derslere katılım sağlayacaklardır. Derse başlamadan önce öğretmen Zoom programından grup sayısı kadar oda açacak ve grup üyelerinin odalarına giriş yapmalarını kontrol edecektir. Heterojen gruplar odalara geçtiklerinde çalışmalarını planlarını oluşturarak bilgi ve ilgilerine göre ünitenin alt konularında uzmanlarını belirleyeceklerdir. Sonra öğretmen, uzman grupları odalarına alacak ve ilgili konuda verilen sürede grupların çalışmasını kontrol edecektir. Uzmanlar asıl gruplarına döndügünde uzman oldukları konuları diğer grup arkadaşlarına öğreterek grup çalışması yapılacaktır. Grup çalışmaları esnasında öğretmen belli zaman aralıkları ile bütün gruplara giderek çalışmaları kontrol edecektir. Kontrol esnasında sorulan sorular programdaki sohbet kısmından da yazılarak bütün öğrenciler tarafindan görülmesi sağlanacaktır. Grup çalışması bittikten sonra bütün sınıf bir araya gelerek kura ile sunum grubu ve soru grubu belirlenecektir. Sunum grubu sunumu yaparken diğer öğrenciler soruları sohbet kısmına yazacaklardır. Soru grubu soruları konu bütünlüğü çerçevesinde soracaktır. Ders dışında gruplar Zoom programı, sosyal medya uygulamaları ve WhatsApp üzerinden farklı gruplar kurarak birlikte çalışma ortamı oluşturulacaktır. Ders dışında da grup çalışması sağlanmaya çalışılacaktır. Değerlendirme aşaması bireysel ve grup olarak yapılacaktır. Grup puanı oluşturulmasındaki amaç grubun önemini anlamak ve birbirlerine bağlı olmasını sağlamaktır. Değerlendirmelerin ardından uygulama sonlandırılacaktır. 


\section{Kaynakça}

Abramczyk, A., \& Jurkowski, S. (2020). Cooperative learning as an evidence-based teaching strategy: What teachers know, believe, and how they use it. Journal of Education for Teaching: International Research and Pedagogy, 46(3), 296-308. https://doi.org/10.1080/02607476.2020.1733402

Açıkgöz, K. Ü. (1992). İşbirlikli öğrenme: Kuram, araştırma ve uygulama. Malatya: Uğurel.

Akbaba, S. (2006). Eğitimde motivasyon. Atatürk Üniversitesi Kazım Karabekir Eğitim Fakültesi Dergisi, $13,343-361$.

Akkuş, A. (2013). Fen ve teknoloji öğretmenlerinin işbirlikli öğrenme modeli hakkında bilgilendirilmesi, bu modeli sınıfta uygulamaları ve elde edilen sonuçların değerlendirilmesi: Muş il örneği, Yayımlanmamış Doktora Tezi. Atatürk Üniversitesi Eğitim Bilimleri Enstitüsü, Erzurum.

Aksoy, G. (2011). Öğrencilerin fen ve teknoloji dersindeki deneyleri anlamalarına okuma-yazma-uygulama ve birlikte ögrenme tekniklerinin etkileri, Yayımlanmamış Doktora Tezi. Atatürk Üniversitesi Eğitim Bilimleri Enstitüsü, Erzurum.

Aronson, E., \& Bridgeman, D. (1979). Jigsaw groups and the desegregated classroom: In pursuit of common goals. Personality and Social Psychology Bulletin, 5(4), 438-446.

Arreguin-Anderson, M. G., \& Esquierdo, J. J. (2011). Overcoming difficulties, Science and Children, 48(7), 68-71.

Bakioğlu, B., \& Çevik, M. (2020). COVID-19 Pandemisi sürecinde fen bilimleri öğretmenlerinin uzaktan eğitime ilişkin görüşleri. Electronic $\quad$ Turkish $\quad$ Studies, 15(4), $109-129$. https://dx.doi.org/10.7827/TurkishStudies.43502

Barkley, E. F., Cross, K. P., \& Major, C. H. (2005). Collaborative learning techniques: A handbook for college faculty. San Francisco: Jossey-Bass.

Bayrakçeken, S., Doymuş, K., \& Doğan, A. (2013). İşbirlikli öğrenme modeli uygulaması. Ankara: Pegem Akademi.

Baytiyeh, H. (2019). Why school resilience should be critical for the post-earthquakere covery of communities in divided societies. Education and Urban Society, 51(5), 693-711. https://doi.org/10.1177/0013124517747035

Burke, J., \& Dempsey, M. (2020). COVID-19 practice in primary schools in Ireland report. National University of Ireland Maynooth, Ireland. https://www.into.ie/app/uploads/2020/04/COVID-19Practice-in-Primary-Schools-Report1.pdf

Can, E. (2020). Coronavirüs (Covid-19) pandemisi ve pedagojik yansımaları: Türkiye'de açık ve uzaktan eğitim uygulamaları. Açıköğretim Uygulamaları ve Araştırmaları Dergisi, 6(2), 11-53.

Cheng, G., \& Chau, J. (2016). Exploring the relationships between learning styles, online participation, learning achievement and course satisfaction: An empirical study of a blended learning course. British Journal of Educational Technology, 47(2), 257-278. https://doi.org/10.1111/bjet.12243

Christison, M. A. (1990). Cooperative learning in the EFL classroom. English Teaching Forum, 28, 6-9.

Colosi, J. C., \& Zales, C. R. (1998). Jigsaw cooperative learning improves biology lab course. Bioscience, $48(2), 118-124$.

Creswell, J. W. (2007). Qualitative inquiry and research design: Choosing among five approaches (2nd ed.). Washington: Sage Publications. 
Çalıklar, Ş., \& Şimşek, Ü. (2017). Takım-oyun-turnuva ve öğrenci takımları başarı bölümleri yöntemlerinin akademik başarı ve kalıcılık üzerine etkisi. Ahi Evran Üniversitesi Kırşehir Eğitim Fakültesi Dergisi, 18(3), 44-63.

Doymuş, K. (2008). Teaching chemical bonding through jigsaw cooperative learning. Research in Science \& Technological Education, 26(1), 47-57. https://doi.org/10.1080/02635140701847470

Ekinci, N. (2011). İşbirliğine dayalı öğrenme. Ö. Demirel (Ed.) Eğitimde yeni yönelimler içinde (ss. 93-109). Ankara: Pegem Akademi Yayıncılık.

Gambari, A. I., Yusuf, M. O., \& Thomas, D. A. (2015). Effects of computer-assisted STAD, LTM and ICI cooperative learning strategies on Nigerian secondary school students' achievement, gender and motivation in physics. Malaysian Online Journal of Educational Sciences, 3(4), 11-26.

Genç, M., \& Şahin, F. (2015). İşbirlikli öğrenmenin başarıya ve tutuma etkisi. Necatibey Eğitim Fakültesi Elektronik Fen ve Matematik Eğitimi Dergisi, 9(1), 375-396.

Gillies, R. M., \& Boyle, M. (2010). Teachers' reflections on cooperative learning: Issues of implementation. Teaching and Teacher Education, 26(4), 933-940.

Gómez, M. (2020). A COVID-19 intervention: Using digital escape rooms to provide professional development to alternative certification educators. Journal of Technology and Teacher Education, $28(2), 425-432$.

Halimah, L., \& Sukmayadi, V. (2019). The Role of "Jigsaw" method in enhancing Indonesian prospective teachers' pedagogical knowledge and communication skill. International Journal of Instruction, 12(2), 289-304. https://doi.org/10.29333/iji.2019.12219a

Hines, C. D. (2008). An investigation of teacher use of cooperative learning with low achieving African American students, Unpublished Doctoral Dissertation. Capella University.

İbicioğlu, H., \& Antalyalı, Ö. L. (2005). Uzaktan eğitimin başarısında imkan algı motivasyon ve etkileşim faktörlerinin etkileri: Karşılaştırmalı bir uygulama. Çukurova Üniversitesi Sosyal Bilimler Enstitüsü Dergisi, 14(2), 325-338.

Johnson, D. W., \& Johnson, R. T. (1999). Making cooperative learning work. Theory into Practice, 38(2), 67-73.

Johnson, D. W., \& Johnson, R. T. (2014). Cooperative learning in the 21st century. Anales de Psicología/Annals of Psychology, 30(3), 841-851. http://dx.doi.org/10.6018/analesps.30.3.201241

Johnson, D. W., Johnson, R. T., \& Stanne, M. B. (2000). Cooperative learning methods: A meta-analysis. Minneapolis, MN: University of Minnesota

Johnson, R.T., Johnson, D. W., \& Holubec, E. J. (1994). New circles of learning: cooperation in the classroom and school. Alexandra, VA, USA: Association for Supervision \& Curriclum Development (ASCD).

Khalil, N., \& Aldridge, J. (2019). Assessing students' perceptions of their learning environment in science classes in the United Arab Emirates. Learning Environments Research, 22(3), 365-386. https://doi.org/10.1007/s10984-019-09279-w

Kim, D. (2018). A Study on the influence of Korean middle school students' relationship through science class applying STAD cooperative learning. Journal of Technology and Science Education, 8(4), 291309. http://dx.doi.org/10.3926/jotse.407

Lara, S., \& Repáraz, C. (2009). Effectiveness of cooperative learning: Webquest as a tool to produce scientific videos. International Conference Eon Multimedia and ICT in Education, Lisbon, Portugal. 
Lee, S. A. (2020). Coronavirus anxiety scale: A brief mental health screener for COVID-19 related anxiety. Death Studies, 44(7), 1-9. https://doi.org/10.1080/07481187.2020.1748481

Loh, R. C., \& Ang, C. (2020). Unravelling cooperative learning in higher education: A review of research. Research in Social Sciences and Technology, 5(2), 22-39. https://doi.org/10.46303/ressat.05.02.2

Macpherson, A. (2015). Cooperative learning group activities for college courses. Surrey, BC Canada: Kwantlen Polytechnic University.

Mulenga, E. M., \& Marbán, J. M. (2020). Is COVID-19 the gateway for digital learning in mathematics education?. Contemporary Educational Technology, $12(2), \quad 11$. https://doi.org/10.30935/cedtech/7949

Nadrah, T., Ismail, A., \& Muhammad Sidin, M. (2017). The effect of cooperative learning model of teams games tournament (TGT) and students' motivation toward physics learning outcome. International Education Studies, 10(2), 123-130.

Oakes, D. J., Hegedus, E. M., Ollerenshaw, S. L., Drury, H., \& Ritchie, H. E. (2019). Using the jigsaw method to teach abdominal anatomy. Anatomical sciences education, 12(3), 272-283.

Okumuş, S., \& Doymuş, K. (2018). Modellerin okuma- yazma- uygulama yöntemi ve yedi ilke ile uygulanmasının maddenin tanecikli yapısı ve yoğunluk konularının kavramsal anlaşılmasına etkisi. Abant İzet Baysal Üniversitesi Eğitim Fakültesi Dergisi, 18(3), 1603-1638.

Okumuş, S. (2020). The effect of cooperative reading-writing-application method on environmental science learning and writing skills development. International Journal of Progressive Education, 16(1), 168191. https://doi.org/10.29329/ijpe.2020.228.13

Orprayoon, S. (2014). Effects of cooperative learning on learning achievement and group working behavior of Junior Students in Modern French Literature course. Journal of Effective Teaching, 14(1), 80-98.

Panigrahi, R., Srivastava, P. R., \& Sharma, D. (2018). Online learning: Adoption, continuance, and learning outcome-A review of literature. International Journal of Information Management, 43, 1-14. https://doi.org/10.1016/j.ijinfomgt.2018.05.005

Patesan, M., Balagiu, A., \& Zechia, D. (2016). The benefits of cooperative learning. International Conference Knowledge-Based Organization, 22(2), 478-483.

Paydar, S., \& Doğan, A. (2019). Öğretmen adaylarının açık ve uzaktan öğrenme ortamlarına yönelik görüşleri. Ĕgitim ve Teknoloji, 1(2), 154-162.

Pınar, M. A., \& Dönel-Akgül, G. (2020a). Medya destekli güncel biyoloji konularının öğretimi hakkında öğretmen adaylarının görüşleri. International Social Sciences Studies Journal, 6(56), 535-546. https://doi.org/10.26449/sssj.2095

Pınar, M. A., \& Dönel-Akgül, G. (2020b). The opinions of secondary school students about giving science courses with distance education during the Covid-19 pandemic. Journal of Current Researches on Social Sciences, 10(2), 461-486. https://doi.org/10.26579/jocress.377

Rosiani, E., Parmin, P., \& Taufiq, M. (2020). Cooperative learning model of group investigation type on students' critical thinking skill and scientific communication skills. Unnes Science Education Journal, 9(1), 48-58.

Sharan, S., \& Sharan, Y. (1992). Expanding cooperative learning through group investigation. New York: Teachers College Press.

Sharan, Y. (2015). Meaningful learning in the cooperative classroom. International Journal of Primary, Elementary and Early Years Education, 43(1), 83-94. https://doi.org/10.1080/03004279.2015.961723 
Siegel, C. (2005). Implementing a research-based model of cooperative learning. The Journal of Educational Research, 98(6), 339-349.

Şimşek Ü. (2012). Effects of two cooperative learning strategies on achievement in chemistry in undergraduate classes. Energy Education Science and Technology Part B, 4(2), 901-912.

Şimşek, Ü. (2007). Çözeltiler ve kimyasal denge konularında uygulanan Jigsaw ve BÖ tekniklerinin ögrencilerin maddenin tanecikli yapıda ögrenmeleri ve akademik başarıları üzerine etkisi, Yayımlanmamış Doktora Tezi. Atatürk Üniversitesi Fen Bilimleri Enstitüsü, Erzurum.

Şimşek, Ü., Doymuş, K., \& Karaçöp, A. (2008). Çözeltiler ünitesinde uygulanan grup araştırması tekniğinin öğrencilerin maddenin tanecikli yapısını anlamalarına ve akademik başarılarına etkisi. Bayburt Üniversitesi Ĕ̈itim Fakültesi Dergisi, 3(1-2), 87-99.

URL-1, 16/11/2020 tarihinde, https://zoom.us/ adresinden erişilmiştir.

Van Dat, T. (2016). The effects of jigsaw learning on students' knowledge retention in Vietnamese higher education. International Journal of Higher Education, 5(2), 236-253. https://doi.org/10.5430/ijhe.v5n2p236

Yılayaz, Ö., \& Barata-Aksoy, Ş. (2020). İşbirlikli öğrenme modelinin 7. sınıf Fen ve Teknoloji dersi “İnsan ve Çevre" ünitesinin öğretiminde öğrenci başarısına etkisi. Turkish Journal of Educational Studies, 7(2), 194-207. https://doi.org/10.33907/turkjes.724374

Yıldırım, A., \& Şimşek, H. (2011). Sosyal bilimlerde nitel araştırma yöntemleri (8. Baskı). Ankara: Seçkin.

Yıldız, E., Çalıklar, Ş., \& Şimşek, Ü. (2020). Gazların kinetik teorisi konusunun öğretiminde üç farklı işbirlikli öğrenme yönteminin etkisi. Buca Eğitim Fakültesi Dergisi, 49, 24-42.

Yüksel, G. (2004). Öğrenme için motivasyon. Ş. Erçetin \& Ç. Özdemir (Ed.) Sinıf yönetimi içinde (ss. 98120). Ankara: Asil Yayınevi.

Zorlu, F. (2016). Fen bilimleri dersinin öğretiminde Solomon araştırma deseninin işbirlikli öğrenme modeline uygulanmasının etkililiğinin incelenmesi, Yayımlanmamış Doktora Tezi. Atatürk Üniversitesi Eğitim Bilimleri Enstitüsü, Erzurum.

Zorlu, Y., \& Sezek, F. (2016). The investigation of effects to learning together method with modeling based learning method on constructivist learning environment. Journal of EKEV Academy, 20(68), 415-430.

Zorlu, F., \& Sezek, F. (2019a). Effectiveness of applying the learning together method at different intervals in teaching science. Acta Didactica Napocensia, 12(29), 195-208. https://doi.org/10.24193/adn.12.2.15.

Zorlu, Y., \& Sezek, F. (2019b). Investigation of the effects of group research method of applying modeling based teaching method in the particle structure and properties of matter unit on constructivist learning. Sakarya University Journal of Education, 9(3), 455-475.

Zorlu, Y., \& Sezek, F. (2020). An investigation of the effect of students' academic achievement and science process skills application together with cooperative learning model and the modeling based teaching method in teaching science courses. International Journal of Progressive Education, 16(4), 135-157. https://doi.org/10.29329/ijpe.2020.268.9 